\title{
Shattered provenance in the digitization of early color films
}

Flückiger, Barbara ; Daugaard, Noemi ; Stutz, Olivia Kristina

Posted at the Zurich Open Repository and Archive, University of Zurich ZORA URL: https://doi.org/10.5167/uzh-203288

Book Section

Published Version

Originally published at:

Flückiger, Barbara; Daugaard, Noemi; Stutz, Olivia Kristina (2021). Shattered provenance in the digitization of early color films. In: Bernardi, Joanne; Cherchi Usai, Paolo; Williams, Tami; Yumibe, Joshua. Provenance and early cinema. Bloomington, Indiana: Indiana University Press, 80-90. 


\section{6}

\section{SHATTERED PROVENANCE IN THE DIGITIZATION OF EARLY COLOR FILMS}

Barbara Flueckiger, Noemi Daugaard, and Olivia Kristina Stutz

$\mathrm{T}$

He AdVent of Digital TeChNology has made iT easier to provide access to early films, but there is little awareness of how deeply digitization severs the ties to the material basis of historical films and to early films in particular. ${ }^{1}$ A majority of the DVDs, Blu-rays, and DCPs currently circulating in cinemas lack information about their source material and digitization process. Ourinvestigations ${ }^{2}$ have confirmed that current digitization practices are detrimental to three fundamental principles of restoration ethics transparency, documentation, and reversibilitythereby shattering the provenance of digitized film. ${ }^{3}$ Transparency refers to intersubjectively defined guidelines that rest on well-grounded knowledge; documentation includes information about the origin of the material objects used for the restoration process and each step in the workflow in a human-readable form; reversibility requires that all the steps are nondestructive, thereby allowing future restorers to apply new insights and better techniques.

To counteract the failings of current digitization practices, the team from the research project European Research Council (ERC) Advanced Grant FilmColors is devising a comprehensive, interdisciplinary approach to the investigation of film colors that includes chemicophysical investigations, advanced documentation of historical film prints, and aesthetic analyses of large groups of films. This approach is being extended by research into the cultural context of film color development 
within the research project Swiss National Science Foundation (SNSF) Film Colors. ${ }^{4}$

These methods aim to safeguard the integrity of the artwork and thus its provenance, a critical requirement of restoration ethics. ${ }^{5}$ Integrity of the artwork includes the systemic relationship between the material manifestation and the philological and aesthetic expression of a film, respectively. Only when the material foundations, the aesthetic appearance, and all analog metadata are translated into the digital domain can we secure the provenance of the digitized version of a film in a transparent, scientifically sound, and thus sustainable way. ${ }^{6}$

\section{Implications of Scanning Early Applied Colors}

As we have noted on several occasions, scanning is a reduction process; in Nelson Goodman's terms, it is a translation info an explicit notation system. ${ }^{7}$ In the discipline of film studies and in archival practice, the processes and implications of film digitization have been rigorously addressed by Paolo Cherchi Usai in his landmark study The Death of Cinema and by Giovanna Fossati in her book From Grain to Pixel. ${ }^{8}$ Nevertheless, little to no attention has been given to the mechanical and optical layout of scanners. Some segments of the professional community have long known that scanning is essentially a black box operation, so it is surprising that customers (film archives, film restorers) did not long ago pressure manufacturers to develop film scanners that are better suited to the ethical requirements of restoration. ${ }^{9}$ In our extensive study Investigation of Film Material-ScannerInteraction, we were looking deeper into these neglected aspects by systematically analyzing key factors of the operation principles of scanners. ${ }^{10}$ This chapter addresses only two of these key factors: the problems involved in capturing early applied colors, and the optics of illumination.

It is widely acknowledged that scanners were not devised for historical color film stocks but rather for more recent chromogenic stocks. As a result, their illumination and sensor setup are generally reduced to three narrow spectral bands that do not match the spectral distribution of early film colors: the dyes and pigments applied in tinting, toning, and hand and stencil coloring. The fact that such a scanner configuration is essentially not a capturing but a measuring device has been largely overlooked. Consequently, two reduction processes-the selective spectral extraction and the binary 
assignment by digitization - add to each other, resulting in severe and unexpected complex distortions to the point where some scanners essentially become color-blind. Once access to the film's color information is cut off, it cannot be retrieved. Moreover, most scanners are not able to capture the full width of the film print, and this cuts off access to important analog metadata in the perforation area. ${ }^{11}$

The second topic that becomes increasingly pressing when we reconsider film digitization is the color appearance in cinema projection, which is highly influenced by the optical arrangement in the projector, the type of illumination (carbon arc, halogen, or xenon), and the properties of the projection screen. Film archivists and restorers have long been aware of the difference between looking at tinted or toned film print on the inspection bench and seeing it projected onscreen, but this difference has never been scientifically investigated. A crucial factor in the different appearance of color in these two contexts, the Callier effect, results from the difference between diffuse and directed-so-called collimated-illumination. ${ }^{12}$ While diffuse illumination scatters between the metallic particles in the film stock, producing lower contrasts, directed illumination causes these metallic particles to completely block out thelight rays, which creates sharper images with higher local contrasts. In his physical investigations for the ERC Advanced Grant FilmColors project, research scientist Giorgio Trumpy provided evidence of the color shift caused by the wavelength dependency of the Callier effect. ${ }^{13} \mathrm{All}$ the professional film scanners that are currently on the market, however, rely on diffuse illumination to prevent hot spots and lower the effect of dust and scratches.

The objective of our new ERC VeCoScan research project is to advance methods of multispectral imaging. Such methods will facilitate capturing the full spectral range of historical color films and the deeper investigation of the chromatic Callier effect with a wider variety of film stocks and scientifically sound, side-by-side projections on historical projectors in the Lichtspiel/Kinemathek in Berne, as executed in 2019. ${ }^{14}$

\section{Film as an Aesthetic Object}

Inspired by Giovanna Fossati's distinction between film as a philological concept-the film as text-and the film as a material object plus the performative dimension of a screening in a specific dispositive, we will argue for an extension to a four-level model for the discussion of film digitization. 
The fourth level to be discussed here is film as an aesthetic object. By film as an aesthetic object, we are referring to the layer between film as a material object and its exhibition or viewing circumstances. This aesthetic interlayer is based on the intrinsic aesthetic expression that governs a work of art and may be limited, altered, or at least influenced by the technological and material constraints of a film at the time of its production. As numerous scholars and film restorers have emphasized, a film's ephemeral status as an aesthetic object is enhanced by the diverse constellation of different film stocks and filmic objects, such as film prints, negatives, and various versions-for example, diverse tinted and toned prints or prints featuring combinations of film color processes. ${ }^{15}$ In addition, we have to understand the temporal influence on a film print's chemical and physical conditions, such as processes of degradation and fading.

With the concept of film as an aesthetic object we address Cesare Brandi's notion of the double historicity of a work of art-the work of art as a witness of the context of its creation and the work of art with traces of its own history. ${ }^{16}$

We use the term faktura to refer tora film stock's three-dimensional materiality. The Russian formalists used this term in the 1910 and 1920 s to describe the texture, surface, and/or materiality of artworks; in this context, the term denotes the layering of the film base, the emulsion, and the dyes and/or colon compounds. The concept of material aesthetics takes into account the close relationship between a film's faktura and its interaction with light, which defines the color rendition in projection. For instance, the chromatic Callier effect is exclusively attributed to the fact that light is scattered or blocked by the particles embedded in the film's emulsion, hence film's material foundation is characterized by its three-dimensionality.

The concepts of affordance and agency as introduced in the material theory by art historian Ann-Sophie Lehmann (based on the reflections by psychologist James J. Gibson and sociologist Bruno Latour) also provide a useful structure for the discussion of material aesthetics. ${ }^{17}$ Lehmann uses affordance to describe different material properties that provide certain aesthetic possibilities or limitations and agency to describe the resulting aesthetic initiatives executed by human actors. ${ }^{18}$ Thus, a film's aesthetics is highly influenced not only by its materiality and its exposure to light but also by contemporary profilmic decisions in production design that in turn respond to the strengths and weaknesses of a certain film stock. 


\section{Film Aesthetics in Relation to Materiality, Affordance, and Agency}

Mimetic two-color films from the 1920 s provide a symptomatic instance for the affordance of color film technology and its agency. These films reproduce only a limited part of the color spectrum from orange-red to bluegreen and are thus intrinsically related to their color process and their set design. Two examples are the famous case of The Black Pirate (Albert Parker, USA, 1926), with its carefully controlled, desaturated color palette of the Caribbean sea in Technicolor No. II, and the Kodachrome Two-Color film Parisian Modes in Colour (Anonymous, USA, 1926), with its haptic display of high-fashion garments in mainly two colors. ${ }^{19}$ In both films, the limited colors are a testament to contemporary color film technologies. There is no reason for a production design consisting of the pure colors blue or purple (agency) because the mimetic two-color technology can't afford to depict those colors accurately in the first place.

This evaluation of affordance and agency in relation to material foundations in early film color processes is crucial for the investigation of the material aesthetics of early film and to notions of film provenance. At the same time, when talking about shattered provenance in the digitization of early films, different colors or entire color processes can also cause certain problems precisely because of their very materiality. For such materialbased obstacles, the method of material iconography established in art history provides a useful framework. This approach centers on the materiality of artworks to illustrate how they gain meaning from their constitutive materials while also acknowledging their sociocultural historicity. ${ }^{20}$ For example, the opaque, oil painting-like "look" of Technicolor No. III is most apparent in its blacks, created by the dye-transfer process in proportion to the colored gelatin matrix. ${ }^{21}$ The more gelatin there is on the matrix, the denser the dye becomes on the faktura, creating a relief effect on the film's surface. The color black, containing all the given colors in a subtractive color synthesis on the blank film, is per se the densest element of every dye-based faktura. It also creates the elevated portions of the relief and embodies the most opaque (black) objects depicted within the film at the same time. Kodachrome Two-Color is a tanning process similar to Technicolor No. II that is often used for black backgrounds, as in Parisian Modes in Colour. In this film it was used not only to make the fabrics pop out but also, according to James Layton, to hide (early) defaults of its technology, like color fringing. ${ }^{22}$ This is another example of the relation between affordance and agency. 
Dye-based blacks from two-color films in relation to silver-based blacks from autonomous applied color processes differ significantly in terms of color density, metallic scattering, and texture. These effects on a film's visual appearance need to be carefully considered when scanning. In addition, digitization of two-color films might also produce difficulties in color grading because of the limited gamut of digital color, while dye fading (for instance the green dye in Technicolor No. II) completely obscures a film's historical aesthetics.

Using scientific material analysis as an extension of material iconography for evaluating material properties and material aesthetics, it is possible to achieve a more authentic rendition of color systems. ${ }^{23}$ This method secures film provenance and the integrity of the film work. This also opens up the question of whether it is possible to retrace film provenance by analyzing large groups of films through digital humanities tools, such as the annotation and analysis tool VIAN used in the ERC EilmColors framework. ${ }^{24}$

\section{Epistemology, Integrity,Digitization}

As we argue above, digitization can compromise a film's integrity on several levels. In addition to material aesthetics, there is a more fundamental consideration: the epistemology that governs a technology. Indeed, the appearance of a film is the result of technological specificities that, in turn, are the product of multilayered influences such as the historical moment and societal context in which they originate. The relationship between technological innovations and society is at the heart of the social construction of technology theory introduced by Wiebe Bijker and Trevor Pinch. In their seminal 1987 work "The Social Construction of Facts and Artifacts," Bijker and Pinch focus on relevant social groups that, because of their specific needs and problems, define what a technological innovation must provide in order to be successfully implemented. ${ }^{25}$ Furthermore, color film technologies respond not only to needs; they also originate from traditions of thought that are strongly connected to scientific discourse. ${ }^{26}$

These foundations shape every color process and, as a result, are inherent to a film's appearance. Therefore, digitizing a color film without respecting these cultural and epistemological factors severs it from a part of its significance and endangers its integrity. In order to avoid such an intervention, it is vital for every digitization to consider its object from various angles. A multifaceted methodology, as advocated by the ERC Advanced 
Grant FilmColors and the SNSF Film Colors projects, allows for a profound understanding of color film, facilitating an ethical approach to digitization that benefits the integrity and provenance of color film.

Color film technology emerged when color was becoming a commodity. Regina Lee Blaszczyk details how the consumer culture of the late nineteenth and early twentieth century was accompanied by the advent of colorful goods, facilitated by the availability of synthetic dyes. ${ }^{27}$ This strong presence of color advanced the efforts to classify and systemize color that had started in the seventeenth century. The color systems of Albert Henry Munsell and Wilhelm Ostwald are only two of several examples that emerged during this period. ${ }^{28}$ In addition, the color revolution led to a new scientific interest in human color perception. As Joshua Yumibe states, "The physiological study of color afterimages led to the theorization of persistence of vision: the notion that an afterimage persists on the eye for a fraction of a second after perceptual stimulation and that this allows for the perception of movement." 29 Yumibe further delineates that, although the theory of persistence of vision has since been refuted-the illusion of movement is now thought to be caused by the so-called phi phenomenon-it remains an important theoretical framework to consider when thinking about the development of early cinematography.

It is no surprise that when film emerged, so did color cinematography. On the one hand, color in film responded to the contemporary need for colorful commodities. On the other hand, the scientific interest in the relationship between color, movement, and perception found its continuation in color cinematography. Additive two-color processes such as Kinemacolor exemplify how nineteenth-century perception theory informed cinematography. ${ }^{30}$ In fact, Kinemacolor was based on the idea that persistence of vision was not only responsible for the perception of movement but could also be used to create the illusion of color. ${ }^{31}$ Kinemacolor was dependent on a set of rotary filters that were dyed red-orange and blue-green. The specific hues used for these filters have their own epistemology, as they stem from a tradition of color theory focusing on primary and complementary colors. Hence, the apparatus and the technology are essential to every Kinemacolor film. The digitization of Kinemacolor and the digital re-creation of its assumed color appearance overthrow the entire epistemology of the process.

Neglecting the cultural and societal foundations of color cinematography compromises the integrity of the filmic object as the product of a culturally and historically localized technology. The reproduction of a process such as Kinemacolor via digital means, or the digitization of tinting 
by partially color-blind film scanners, represents a separation of the work from its technology. In addition to being arbitrary, such a process is problematic in terms of cultural and technological heritage and in the way it shatters a film's provenance.

\section{Conclusion}

Our paper has shown that we need contextual research and information in order to develop digitization processes that respect the basic requirements of restoration ethics. To date, the institutional aspects of technical service providers and the often-limited personal and financial resources of clients fail to bring about changes resulting in digitization that is aligned with indepth scholarly and scientific insights. While changing insights and practices have always been part of the restoration process, weneed to anticipate future technological developments, such as ultra wide-gamut projection systems, high-dynamic range contrast rendition, and higher frame rates that would allow for the emulation of a mechanical shutter in accordance with historical projection technologies.

As we have previously stated, we should aim for technologies that fully capture film as a three-dimensional object with all the physical and chemical properties film comprisès as a material object. ${ }^{32}$ This includes the vital analog metadata that contains additional information about a film's provenance. There are many technologies in the field of computational photography that are already partially applied to the documentation and investigation of artworks. These advanced computational techniques will capture the multilayered structure and three-dimensional material properties of film, or the full contrast range with high-dynamic range imaging. Hopefully, such methods will one day create a comprehensive reconstruction of analog films by means of a technology yet to be invented.

\section{Acknowledgments}

This project has received funding from the European Research Council under the European Union's Horizon 2020 research and innovation program, grant agreement No. 670446 FilmColors.

\section{Notes}

1. See Paolo Cherchi Usai, The Death of Cinema: History, Cultural Memory and the Digital Dark Age (London: BFI, 2001) and Giovanna Fossati, From Grain to Pixel: The Archival Life of Film in Transition (Amsterdam: Amsterdam University Press, 2009). 
2. DIASTOR https://diastor.ch/ and our current project ERC Advanced Grant FilmColors, http://filmcolors.org/2015/06/15/erc/. (accessed November 27, 2018).

3. Cesare Brandi, Teoria del restauro (Turin: Einaudi, 1977).

4. See research project Film Colors. Technologies, Cultures, Institutions, funded by the Swiss National Science Foundation, accessed June 15, 2020, https://www.film.uzh.ch/en/rese arch/projects/verbund/SNSF-FilmColors.html.

5. See Fédération Internationale des Archives du Film, "FIAF Code of Ethics" (2008).

6. As described by Harold Brown, Physical Characteristics of Early Films as Aids to Identification (Brussels: FIAF, 1990).

7. See for instance Barbara Flueckiger, "Material Properties of Historical Film in the Digital Age," NECSUS. European Journal of Media Studies 1, no. 2 (2012): 135-153; Barbara Flueckiger, Claudy Op den Kamp, Franziska Heller, and David Pfluger, “Digital Desmet': Translating Early Applied Colors," The Moving Image 16, no. 1 (2016): 106-124; Barbara Flueckiger, Claudy Op den Kamp, David Pfluger, "A Material-Based Approach to the Digitization of Early Film Colours," in The Color Fantastic: Chromatic Worlds of Silent Cinema, ed. Giovanna Fossati et al. (Amsterdam: Amsterdam University Press, 2018), 237-259; and Barbara Flueckiger, David Pfluger, Giorgio Trumpy, Simone Croci, Tunç Aydın, and Aljoscha Smolic, Investigation of Film Material-Scanner Interaction (2018): 88, available online, accessed November 27, 2018, https://diastor.ch/results/; and Nelson Goodman, Languages of Art. An Approach to a Theory of Symbols (Indianapolis: Hackett Publishing Company, 1968, 1978 edition), 159.

8. See Paolo Cherchi Usai, The Death of Cinema: History, Cultural Memory and the Digital Dark Age (London: BFI, 2001) and Giovanna Fossati, From Grain to Pixel: The Archival Life of Film in Transition (Amsterdam: Amsterdam University Press, 2009).

9. See for instance Thomas C. Christensen, "Restoring a Danish Silent Film," in Preserve Then Show, ed. Dan Nissen (Copenhagen: Danish Film Institute, 2002), 141.

10. Flueckiger et al., Investigation of Film Material-Scanner Interaction.

11. See Ibid.

12. As described by André Callier, "Absorption und Diffusion des Lichtes in der entwickelten photographischen Platte, nach Messungen mit dem Martensschen Polarisationsphotometer," Zeitschrift Für Wissenschaftliche Photographie 7 (1909): 257.

13. Giorgio Trumpy and Barbara Flueckiger, "Chromatic Callier Effect and Its Repercussions on the Digitization of Early Film Colors," Journal of Imaging Science and Technology 63, no. 1 (January 2019): 010506-1-010506-11.

14. Research project ERC Proof of Concept: Development of a New Versatile Archival Film Scanner (VeCoScan), led by Barbara Flueckiger (2018-2020), see https://www.film.uzh .ch/de/research/projects/archive-projects.html (accessed June 15, 2020).

15. See discussion in Bregt Lameris, The Film Museum Practice and Film Historiography: The Case of the Nederlands Filmmuseum (1946-200o) (Amsterdam: Amsterdam University Press, 2017), 120.

16. Cesare Brandi, Teoria del restauro (Turin: Einaudi, 1977), 6.

17. See James J. Gibson, The Senses Considered as Perceptual System (Boston: Houghton Mifflin, 1966) and James J. Gibson, The Ecological Approach to Visual Perception (Boston: Houghton Mifflin, 1979) as well as Bruno Latour, Reassembling the Social: An Introduction to Actor-Network-Theory (Oxford: University Press, 2005).

18. See Ann-Sophie Lehmann, "Das Medium als Mediator: Eine Materialtheorie für (Öl)Bilder," Zeitschrift für Ästhetik und Allgemeine Kunstwissenschaft 57, no. 1 (2012): 69-88. 
19. As described by John Belton, “Taking the Color Out of Color': Two-Color Technicolor, The Black Pirate, and Blackened Dyes," in The Color Fantastic: Chromatic Worlds of Silent Cinema, ed. Giovanna Fossati et al. (Amsterdam: Amsterdam University Press, 2018), 97-108.

20. See Monika Wagner, Das Material der Kunst: Eine andere Geschichte der Moderne. (München: Beck, 2001). Adapted to film studies, the method focuses on analog film materiality targeting the material bases of film objects (faktura) and the profilmic arrangement of the set design in relation to the depicted materials in the mise-en-scène as a result of a causal depiction process. Both the method and concept will be the focus of the forthcoming PhD thesis by Olivia Kristina Stutz on early color film.

21. Ulrich Ruedel, "The Technicolor Notebooks at the George Eastman House," Film History 21, no. 1 (2009): 47-60.

22. See James Layton, "Two-Color Kodachrome Test Shots No. III (1922)" (Library of Congress National Film Preservation Board, n.d.), available online, accessed November 27, 2018, https://www.loc.gov/programs/static/national-film-preservation-board/documents /kodachrome.pdf.

23. See Flueckiger, Op den Kamp, Pfluger, "A Material-Based Approach to the Digitization of Early Film Colours" (2018), and Masaki Daibo, Tomohiro Hasegawa, Kasuki Miura, "Limiting Color Grading for Two-Color Film Restoration. Utilising a Spectroradiometer to Create a Specific LUT," Journal of Film Preservation 96, no. 4 (2017): 97-106.

24. See Barbara Flueckiger, "A Digital Humanities Approach to Film Colors," The Moving Image 17, no. 2 (2017): 71-94.

25. Trevor J. Pinch and Wiebe E. Bijker, "The Social Construction of Facts and Artifacts," in The Social Construction of Technological Systems. New Directions in the Sociology and History of Technology, ed. Wiebe E. Bijkeret al. (Cambridge, MA: MIT Press, 1987), 17-50.

26. An in-depth analysis of these topics, which can only be briefly introduced for the scope of this contribution, is an integral part of Noemi Daugaard's forthcoming $\mathrm{PhD}$ thesis in the framework of the SNSF research project, Film Colors. Technologies, Cultures, Institutions.

27. Regina Lee Blasżczyk, The Color Revolution (Cambridge, MA: MIT Press, 2012).

28. A leading topic of these works was the concept of color harmony. In fact, most color systems are based on normative conceptions of harmonious color combinations and often include rules, or even mathematical formulas, to determine which colors should be combined. See for instance Albert Henry Munsell, Atlas of the Munsell Color System (Malden, MA: Wadsworth, 1915) and Albert Henry Munsell, A Color Notation (New York: Munsell Color Co., 1919) as well as Wilhelm Ostwald, Die Farbenfibel (Leipzig: Verlag Unesma, 1917) and Wilhelm Ostwald, Die Harmonie der Farben (Berlin: Verlag Unesma, 1918).

29. See Joshua Yumibe, Moving Colors. Early Film, Mass Culture, Modernism (New Brunswick, NJ: Rutgers University Press, 2012), 17.

30. Kinemacolor was invented in 1908 by Charles Urban and George Albert Smith; for more information see Timeline of Historical Film Colors, accessed November 27, 2018, http:// zauberklang.ch/filmcolors/timeline-entry/1214/.

31. For a more detailed description, see Benoît Turquety, "The Illusion of Movement, the Illusion of Color: The Kinemacolor Projector, Archaeology, and Epistemology," in Exposing the Film Apparatus: The Film Archive as a Research Laboratory, ed. Giovanna Fossati and Annie van den Oever (Amsterdam: Amsterdam University Press/EYE, 2016), 223-231 and 
Benoit Turquety, "Why Additive? Problems of Color and Epistemological Networks in Early (Film) Technology," in The Color Fantastic: Chromatic Worlds of Silent Cinema, ed. Giovanna Fossati et al. (Amsterdam: Amsterdam University Press, 2018), 109-123.

32. See Flueckiger, "Material Properties of Historical Film in the Digital Age" (2012), Flueckiger, Op den Kamp, Pfluger, "A Material-Based Approach to the Digitization of Early Film Colours" (2018), and Flueckiger et al., Investigation of Film Material-Scanner Interaction.

BARBARA FLUECKIGER is Professor of Film Studies at the University of Zurich. She is author of Color Mania: The Material of Color in Photography and Film and creator of the Timeline of Historical Film Colors.

NOEMI DAUGAARD is a PhD candidate at the University of Zuirich. She is author of Grauenvolle Atmosphären: Tondesign und Farbgestaltung als affektive und subjektivierende Stilmittel in "The Silence of the Lambs."

OLIVIA KRISTINA STUTZ is a PhD candidate at the University of Zurich, and a regular contributor to the Timeline of Historical Film Colors. 